\title{
EFFECT OF LOW DIETARY PROTEIN SOURCES ON THE INTESTINAL MICROBIOTA OF FINISHING PIGS
}

\author{
SUN, K. C. ${ }^{1,2,3}-$ CAO, K. F. ${ }^{1,2,3}-$ ZHAO, L. ${ }^{1,2,3}-$ SU, S. $.^{1,2,3}-$ GENG, T. T. ${ }^{1,2,3}-$ HE, F. ${ }^{1,2,3}-$ \\ BAI, X. L. ${ }^{1,2,3}-$ ZHANG, H. H. ${ }^{1,2,3}-$ GUO, H. L. ${ }^{1,2,3}-$ SUN, H. ${ }^{1,2,3 *}$ \\ ${ }^{1}$ College of Animal Science and Technology, Jilin Agricultural University, Changchun 130118, \\ P. R. China
}

${ }^{2}$ Key Laboratory of Animal Production, Product Quality and Security, Ministry of Education, Jilin Agricultural University, Changchun 130118, P. R. China

${ }^{3}$ Jilin Provincial Key Laboratory of Animal Nutrition and Feed Science, Jilin Agricultural University, Changchun 130118, P. R. China

*Corresponding author

e-mail: hui1688@163.com; phone: +86-189-4392-1381

(Received 24 $4^{\text {th }}$ Sep 2020; accepted $19^{\text {th }}$ Jan 2021)

\begin{abstract}
The objective of this study was to evaluate the effect of low dietary protein sources on the gut microbiota in finishing pigs. Thirty-six Duroc $\times$ Landrace $\times$ Large White finishing barrows were randomly allocated to four equal groups. Soybean meal (SBM) as a protein source is a control group and had a general protein level of 15\% (SBM15). The pigs fed soybean meal (SBM11), soybean-cottonseedcorn germ meal (SCCM11), and cottonseed-corn germ meal (CCM11) were offered low protein (11\%) diets. The results showed that the ileum and feces microbiota of the SCCM11 group were significantly increased compared to the SBM15 group $(P<0.05)$. At the phylum level, the relative abundance of Proteobacteria phyla was significantly increased in the ileum microbiota of the SCCM11 group compared to the SBM15 group $(P<0.05)$. At the genus level, the abundance of Lactobacillus and Bifidobacterium showed a significant increase in the ileum microbiota of the SCCM11 group $(P<0.05)$. The abundance of Ruminococcaceae, Phascolarctobacterium was significantly increased in the feces microbiota of the SCCM11 group than the other three groups $(\mathrm{P}<0.05)$. These results indicated that the SCCM11 group with added crystalline amino acid may modulate intestinal microbiota.

Keywords: soybean-cottonseed-corn germ meal, ileum microorganisms, fecal microorganisms, intestinal health, 16SrRNA
\end{abstract}

\section{Introduction}

Intestinal health is associated with the growth of pigs (Zhou et al., 2015). Commonly, intestinal microbiota plays an important role in intestinal healthy (Brestoff and Artis, 2013). Because of the impact on physiological, nutrition, and immunological process, the intestinal microbiota is a uniquely diverse ecosystem that influences many aspects of its host (McDonald et al., 2018).

Wellock et al. (2006) demonstrated that a decrease in dietary protein intake results in higher fecal and colonic lactobacilli to the coliform ratio in pigs. Additionally, Rist et al. (2014) reported that variations in dietary protein supply may beneficially affect microbiota composition in the intestinal tract of pigs. Cottonseed meal (CSM) and corn germ meal (CGM) have been used in the non-ruminant animal diets and shown to achieve good results, such as improve bacterial diversity (González-Vega and Stein, 2012). From previous studies, we can see that suitable protein sources and low protein (LP) levels can be used in finishing pigs' diets and influence the composition and function of intestinal microbiota. 
Diet composition has been identified as one of the important factors that influence the composition of intestinal microbiota (Liao et al., 2017). Amino acid is an important part of the diet that can support the growth of bacteria and host (Morales et al., 2012). These microbes also can utilize amino acids to offer nutrition for hosts and are beneficial for the balance of intestine microecological and guaranteed the health and development of intestine (Dersjant-Li et al., 2019).

This study aims to determine LP diets with different protein sources including Soybean meal (SBM), CSM, CGM in feeding finishing pigs as well as to estimate the intestinal microbiota. These were assessed through high-throughput sequencing-based on Illumina Miseq to define the diversity, abundance, and composition of ileum and feces microbiota in finishing pigs.

\section{Material and methods}

\section{Animals, housing}

Thirty-six (Duroc $\times$ Landrace $\times$ Large White) finishing barrow pigs (Ji Feng Company, Gongzhuling, China), according to initial body weight (BW, $58.65 \pm 3.71 \mathrm{~kg}$ ) were randomly allocated to four groups using a randomized block design and the sex was considered as a random effect. Each group consisted of three replicates (pens) and three pigs each. Every pig was in a single cage $(150 \mathrm{~cm}$ in length $\times 70 \mathrm{~cm}$ in width), the pre-feeding period was 7 days, formal feeding period was 28 days. All pigs were conducted at Farm of Jilin Agriculture University, Changchun city, China. The pigs were kept individually throughout the experimental period. All animals had unlimited access to feed and water throughout the experimental period. The average of the ambient temperature in the barn was $25^{\circ} \mathrm{C}$. The treatment, housing, husbandry, and slaughtering conditions conformed to the Guide for the Care and Use of Laboratory Animal (2012).

\section{Diets}

The experimental diets referred to the feeding standard of finishing pigs (NRC, 2012, $50-80 \mathrm{~kg}$ ) and were formulated by the net energy system. SBM as a protein source is a control group and had a general protein level of 15\% (SBM15). The pigs in the SBM11, soybean-cottonseed-corn germ meal (SCCM11), and cottonseed-corn germ meal (CCM11) groups as treatment groups were offered LP level (11\%) diets (Table 1). All experimental diets were meet the requirement of standardized ileum digestibility (SID) of amino acid in finishing pigs and balanced with some crystalline amino acid (NRC, 2012).

\section{Sample}

On the day 29th, all the pigs were fasted for $12 \mathrm{~h}$ before slaughter and slaughtered at the slaughterhouse in Jilin Agriculture University via electrical stunning followed by exsanguination. The pigs were opened up immediately. The ileum content and feces in the rectum were collected into tubes (freezing, approximately $5 \mathrm{~cm}$ in length $\times 1 \mathrm{~cm}$ in width, huayi biological Company, China). Samples kept in liquid nitrogen were immediately and at $-80^{\circ} \mathrm{C}$ until further analysis. 
Table 1. Composition and nutrient analysis of experimental diets

\begin{tabular}{|c|c|c|c|c|}
\hline \multirow{2}{*}{ Diets } & \multirow{2}{*}{$\begin{array}{c}\text { Normal protein }(15 \% \mathrm{CP}) \\
\text { SBM15(2) }\end{array}$} & \multicolumn{3}{|c|}{ Low protein $(11 \% \mathrm{CP})$} \\
\hline & & SBM11 2 & SCCM11(2) & CCM112) \\
\hline Maize $(8.7 \% \mathrm{CP})$ & 71.50 & 77.50 & 77.00 & 76.60 \\
\hline Soybean meal $(44.0 \% \mathrm{CP})$ & 18.00 & 6.00 & 3.00 & - \\
\hline Cottonseed meal ( $40.6 \% \mathrm{CP})$ & - & - & 2.45 & 4.90 \\
\hline Corn germ meal $(20.8 \% \mathrm{CP})$ & - & - & 1.76 & 3.52 \\
\hline Rice hull powder & 1.29 & 2.82 & 2.22 & 1.63 \\
\hline Soybean oil & 4.05 & 5.50 & 5.50 & 5.50 \\
\hline Lysine $(98 \%)$ & 0.25 & 0.59 & 0.65 & 0.70 \\
\hline Methionine (98\%) & 0.36 & 0.43 & 0.43 & 0.43 \\
\hline Threonine (98\%) & 0.17 & 0.34 & 0.36 & 0.38 \\
\hline Typtophan (98\%) & 0.06 & 0.11 & 0.11 & 0.11 \\
\hline Isoleucine (98\%) & - & 0.24 & 0.27 & 0.30 \\
\hline Leucine (98\%) & 0.06 & 0.26 & 0.29 & 0.32 \\
\hline Valine $(98 \%)$ & 0.09 & 0.27 & 0.27 & 0.27 \\
\hline Phenylalanine (98\%) & 0.05 & 0.25 & 0.25 & 0.25 \\
\hline Histidine (80.1\%) & 0.04 & 0.14 & 0.15 & 0.14 \\
\hline Dicalcium phosphate & 0.72 & 0.86 & 0.81 & 0.78 \\
\hline Limestone & 0.94 & 0.96 & 1.00 & 1.02 \\
\hline Salt & 0.30 & 0.30 & 0.30 & 0.30 \\
\hline Zeolite & 1.12 & 2.43 & 2.18 & 1.85 \\
\hline Vitamin and mineral premix (1) & 1.00 & 1.00 & 1.00 & 1.00 \\
\hline \multicolumn{5}{|l|}{ Nutrition composition } \\
\hline Net energy (kcal/kg) & 2475.42 & 2475.81 & 2474.61 & 2475.48 \\
\hline Crude protein & 14.93 & 10.97 & 11.04 & 11.08 \\
\hline Lys & 0.91 & 0.91 & 0.91 & 0.91 \\
\hline Met+Cys & 0.51 & 0.51 & 0.51 & 0.51 \\
\hline Thr & 0.56 & 0.55 & 0.56 & 0.56 \\
\hline $\operatorname{Trp}$ & 0.17 & 0.17 & 0.16 & 0.16 \\
\hline Ile & 0.47 & 0.47 & 0.47 & 0.48 \\
\hline Leu & 0.94 & 0.91 & 0.91 & 0.91 \\
\hline Phe & 0.59 & 0.59 & 0.59 & 0.59 \\
\hline Val & 0.54 & 0.55 & 0.54 & 0.54 \\
\hline His & 0.31 & 0.31 & 0.32 & 0.31 \\
\hline $\mathrm{Ca}$ & 0.59 & 0.59 & 0.59 & 0.59 \\
\hline
\end{tabular}

Note:

(1)Premix per kg diet provided: cobalt $1 \mathrm{mg}$; copper $150 \mathrm{mg}$; iron $150 \mathrm{mg}$; manganese $80 \mathrm{mg}$; zinc $120 \mathrm{mg}$; iodine $0.3 \mathrm{mg}$; selenium $0.3 \mathrm{mg}$; nicotinic acid $10 \mathrm{mg}$; calcium pantothenate $5 \mathrm{mg}$; folic acid $0.4 \mathrm{mg}$; biotin $0.05 \mathrm{mg}$; retinal 38,000,000 IU; cholecalciferol 8,000,000 IU; alpha-tocopherol 90,000 $\mathrm{IU}$; menadione $1 \mathrm{mg}$; thiamin mononitrate $1 \mathrm{mg}$; riboflavin $2 \mathrm{mg}$; pyridoxine hydrochloride $1.2 \mathrm{mg}$; cyanocobalamin $0.01 \mathrm{mg}$; antioxidant $0.02 \mathrm{mg}$.

(2) SBM15 represents soybean meal (SBM) and crude protein (CP) level is 15\%. SBM11 represents SBM and the CP level is 11\%. SCCM11 represents soybean-cottonseed-corn germ meal (SCCM) and the CP level is $11 \%$. CCM11 represents cottonseed-corn germ meal (CCM) and CP level is $11 \%$ 


\section{High- throughput sequencing}

Total sample DNA was extracted with a QIAamp® DNA Stool Mini Kit (QIAGEN Company, USA) (Sbardella et al., 2016). The concentration of the extracted DNA was determined using 1\% agarose gel electrophoresis (Ren et al., 2013). The bacterial 16SrRNA gene was amplified with a set of primers targeting the V3-V4 region and the primers were 338F (5'- ACTCCTACGGGAGGCAGCAG -3') and 806R (5'GGACTACHVGGGTWTCTAAT -3'). The PCRs were carried out in triplicate using $20 \mu \mathrm{L}$ reactions with $4 \mu \mathrm{L}$ of $5 \times$ FastPfu buffer, $2 \mu \mathrm{L}$ of $2.5 \mathrm{mM}$ dNTPs, $0.8 \mu \mathrm{L}$ of 5 $\mu$ mol 1-1 each primer, $0.4 \mu \mathrm{L}$ of FastPfu polymerase, $10 \mathrm{ng}$ of DNA, and added ddH2O to $20 \mu \mathrm{L}$, according to the manufacturer's instructions. The PCR amplification was conducted according to described by Metzler-Zebeli et al. (2009). Initial denaturation at $95^{\circ} \mathrm{C}$ for $3 \mathrm{~min}$, followed by 27 cycles of $95^{\circ} \mathrm{C}$ for $30 \mathrm{~s}$, annealing at $55^{\circ} \mathrm{C}$ for $30 \mathrm{~s}$, extension at $72^{\circ} \mathrm{C}$ for $45 \mathrm{~s}$, with a final elongation step at $72^{\circ} \mathrm{C}$ for $10 \mathrm{~min}$. The concentrations of each PCR product were checked by agarose gel electrophoresis (2\% agarose) and SanPrep Column DNA Gel Extraction Kit (Biotech, Sangon Company, China) to ensure correct primer specific products (Agyekum et al., 2016). Quantity and quality of purified PCR amplification products were determined using QuantiFluor ${ }^{\circledR}$ Single-Tube Fluorometers (Promega Company, USA) (Castillo et al., 2006). Highthroughput sequencing was performed on Illumina Miseq (PE300) sequencing platform at Majorbio Bio-Pharm Technology Co., Ltd. (Meiji Company, China).

\section{Bioinformatics analysis}

All of the sequences were analyzed and filtered according to the barcode and primer sequences using Trimmomatic software. Raw reads were processed to remove low-quality sequences if they were shorter than $300 \mathrm{bp}$ or longer than the expected PCR product size. Operational taxonomic units (OTUs) were chosen, which were defined by 97\% of similarity, using the Usearch (version 7.1). According to Ribosomal Database Project (RDP) classifiers against the Silva 16SrRNA database (Quast et al., 2013) assigned taxonomically and calculation abundance, make rarefaction curves of microbe structure, the figure of Species abundance and principal components analysis (PCA) (Qiong et al., 2007). Rarefaction curves, Shannon index, abundance-based coverage estimator (ACE) index, and Chao1 richness were determined using Mothur (version v.1.30.1) (Schloss et al., 2011). Beta diversity was evaluated with the Unifrac metric. Weighted Unifrac distance matrices were used to compare the hierarchical relationships among the samples (Lozupone et al., 2011).

\section{Statistical analysis}

All experimental data were initially subjected to analysis of variance (ANOVA) with General Linear Model (GLM) procedures of SPSS software (19.0, SPSS Inc, Chicago, IL, U.S.) using a randomized block design. Growth performance was analyzed with the pen as the experimental unit $(n=9)$; Microbiota diversity, abundance, and composition of ileum and feces were analyzed with the pen as the experiment unit $(n=6)$. When the interactions were significant $(P<0.05)$ for most of the parameters, data were then analyzed using one-way ANOVA among the groups within a diet. When F-test was significant $(P<0.05)$, the least significant difference (LSD) test was utilized to compare significant differences $(P<0.05)$ among the groups. 


\section{Results}

\section{Effect of variations in dietary protein levels with different protein sources on the diversity of ileum and feces bacterial}

The diversity of bacterial based on OTUs and estimated OTUs from ACE, Chao 1, and Shannon indices. It reflects the bacterial diversity in the sample. A total of 658,744 valid reads and 660 OTUs were obtained from 48 samples through Illumina Miseq analysis after screening them with strict criteria. The diversity estimates of the pig ileum and feces were shown in Table 2. For the ileum samples, the SBM11 group richness the number of OTUs and estimated OTUs from Shannon compared with the SBM15 group $(P<0.05)$. The number of OTUs and estimated OTUs from the ACE, Chao 1 indices showed that the SCCM11 and CCM11 groups were much higher than the SBM15 and SBM11 group $(P<0.05)$. The number of OTUs, Chao 1 , and ACE indices of the SCCM11 group was higher than the other three groups $(P>0.05)$. For the feces samples, the number of OTUs of the SBM11 and SCCM11 groups was significantly higher than the SBM15 group $(P<0.05)$. The number of OTUs and Chao 1 indices showed that the SCCM11 group was significantly higher than the groups of SBM15 and SBM11 $(P<0.05)$.

Table 2. Effect of low protein diet and different protein sources on diversity estimation of the 16S rRNA gene libraries from ileum and feces microbiota in finishing pigs $(n=6)$

\begin{tabular}{c|c|c|c|c|c}
\hline Items & Group & OTU & ACE & Chao1 & Shannon \\
\hline \multirow{7}{*}{ Ileum } & SBM15 & $42.333 \pm 10.504^{\mathrm{c}}$ & $53.662 \pm 5.670^{\mathrm{c}}$ & $53.323 \pm 17.287^{\mathrm{b}}$ & $1.353 \pm 0.295^{\mathrm{b}}$ \\
& SBM11 & $60.667 \pm 6.028^{\mathrm{b}}$ & $66.210 \pm 3.045^{\mathrm{c}}$ & $66.333 \pm 15.939^{\mathrm{b}}$ & $2.037 \pm 0.057^{\mathrm{a}}$ \\
& SCCM11 & $85.067 \pm 12.133^{\mathrm{a}}$ & $206.067 \pm 35.388^{\mathrm{a}}$ & $157.250 \pm 23.750^{\mathrm{a}}$ & $1.960 \pm 0.433^{\mathrm{ab}}$ \\
& CCM11 & $83.7500 \pm 7.2500^{\mathrm{a}}$ & $127.517 \pm 23.000^{\mathrm{b}}$ & $128.520 \pm 25.517^{\mathrm{a}}$ & $1.820 \pm 0.080^{\mathrm{b}}$ \\
& P value & 0.050 & 0.049 & 0.045 & 0.053 \\
\hline \multirow{6}{*}{ Feces } & SBM15 & $382.333 \pm 29.501^{\mathrm{b}}$ & $459.000 \pm 37.363$ & $365.000 \pm 43.313^{\mathrm{b}}$ & $4.447 \pm 0.119$ \\
& SBM11 & $318.0000 \pm 22.338^{\mathrm{c}}$ & $475.000 \pm 12.124$ & $481.667 \pm 20.033^{\mathrm{b}}$ & $4.280 \pm 0.131$ \\
& SCCM & $459.667 \pm 25.686^{\mathrm{a}}$ & $489.000 \pm 10.149$ & $496.667 \pm 18.963^{\mathrm{a}}$ & $4.560 \pm 0.125$ \\
& CCM & $419.000 \pm 14.933^{\mathrm{ab}}$ & $462.333 \pm 21.008$ & $484.000 \pm 36.056^{\mathrm{a}}$ & $4.347 \pm 0.318$ \\
& P value & 0.047 & 0.414 & 0.042 & 0.368 \\
\hline
\end{tabular}

Different letters in the same column identify significant differences at 0.05 level among parameters. SBM15 represents soybean meal (SBM) and the crude protein (CP) level is $15 \%$. SBM11 represents SBM and the CP level is $11 \%$. SCCM11 represents soybean-cottonseed-corn germ meal (SCCM) and the $\mathrm{CP}$ level is $11 \%$. CCM11 represents cottonseed-corn germ meal (CCM) and the CP level is $11 \%$

The analysis of bacterial community structure is mainly based on principal component analysis (PCA). It is based on the distance to describe the relationship between samples. The pig ileum and feces were divided into two groups based on PCA (Fig. 1) and the unweighted pair group method with arithmetic mean (UPGMA) from the Unifrac and Mothur analyses (Fig. 2). Pairwise comparisons revealed that the bacterial community structure of ileum samples in SBM15, SBM11, SCCM11, and CCM11 groups showed a high level of distance to feces samples for SBM15, SBM11, SCCM11, and CCM11 groups. Additionally, rarefaction curves from the ileum and feces microbiome appear to approach a horizontal asymptote, indicating that the current sequencing effort saturates diversity (Fig. 3). However, the distance of bacterial community structures in ileum or feces was very short among the four groups. 
PCA

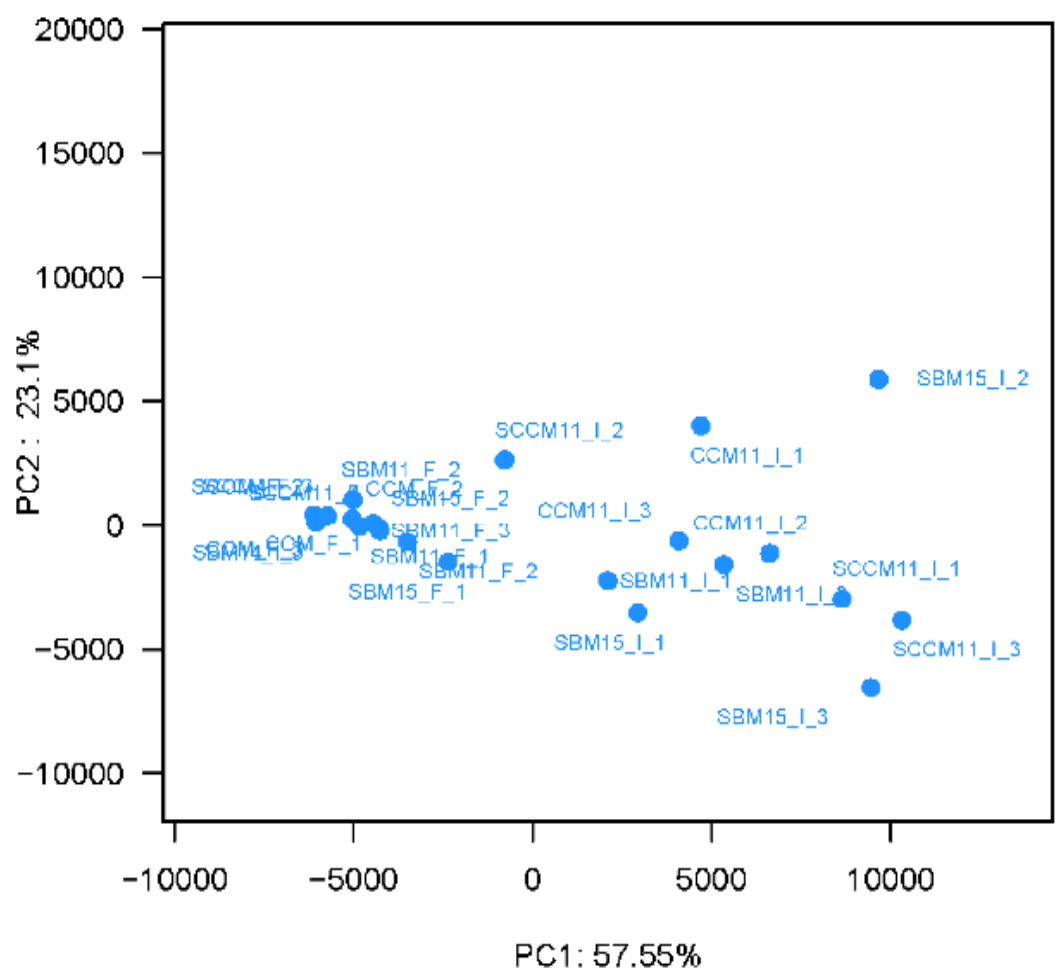

Figure 1. The score plot of principal component analysis for different bacterial communities using weighted Unifaces distance. This analysis is based on principal component analysis (PCA) and the distance describes the relation between samples. SBM15 represents soybean meal (SBM) and the crude protein (CP) level is 15\%. SBM11 represents SBM and the CP level is $11 \%$. SCCM11 represents soybean-cottonseed-corn germ meal (SCCM) and the CP level is $11 \%$. CCM11 represents cottonseed-corn germ meal (CCM) and CP level is $11 \%$. The "I" represent ileum; " $F$ " represents feces. The number, in the end, is pig number (one to three pigs). To make the figure clear, I did not put all pig number (one to six pigs)

Effects of variations in dietary protein levels with different protein sources on the abundance and composition of ileum and feces microbiota for phylum and genus level

In order to evaluate the abundance and composition of ileum and feces microbiota, a phylum and genus level was a calculation to define the microbiota of ileum and faces. At the phylum level, the pig ileum microbiomes of four groups were dominated by the Firmicutes phyla (Fig. 4). The result showed that three LP diets significantly increased the relative abundance of Proteobacteria phyla $(P<0.05)$. The pig fecal microbiomes among the dietary treatments had no effect on the bacterial community composition. Firmicutes, Bacteroidetes, Proteobacteria, and Spirochaetae amounting to beyond 99\% of the total reads.

At the genus level, the most predominant genus in SBM15, SBM11, SCCM11, and CCM11 were the Clostridium sensu stricto, Terrisporobacter, Peptostreptococcaceae, and Turicibacter genus in the ileum (Fig. 5). The SBM15 diet significantly decreased the abundance of Actinobacillus (0.501\%), Lactobacillus (0.017\%), and Bifidobacterium (0\%) $(P<0.05)$, but increased the abundance of Streptococcus $(2.895 \%)$ 
comparing to the three LP diets groups $(P<0.05)$. The SCCM11 group diet significantly increases the abundance of Lactobacillus (5.214\%) and Bifidobacterium (3.923\%) comparing to the other three groups $(P<0.05)$ (Table 3). In the feces, four diet groups library included sequences most similar to Clostridium sensu stricto, Terrisporobacter, Peptostreptococcaceae, Rikenellaceae, Treponema, Christensenellaceae, Lachnospiracea and Prevotella (Fig. 5). The SBM15 group significantly increase the abundance of Streptococcus $(7.785 \%)$ and Anaerovibrio $(1.394 \%)$ genus $(P<0.05)$ and a lower relative abundance of Prevotellaceae UCG-001 (0.243\%) $(\mathrm{P}<0.05)$ than the three LP groups. Nevertheless, Ruminococcaceae UCG-014 (2.882\%), Phascolarctobacterium (1.496\%) and Oscillibacter $(1.426 \%)$ were more abundant in the SCCM11 group than the other three groups $(P<0.05)($ Table 3$)$.

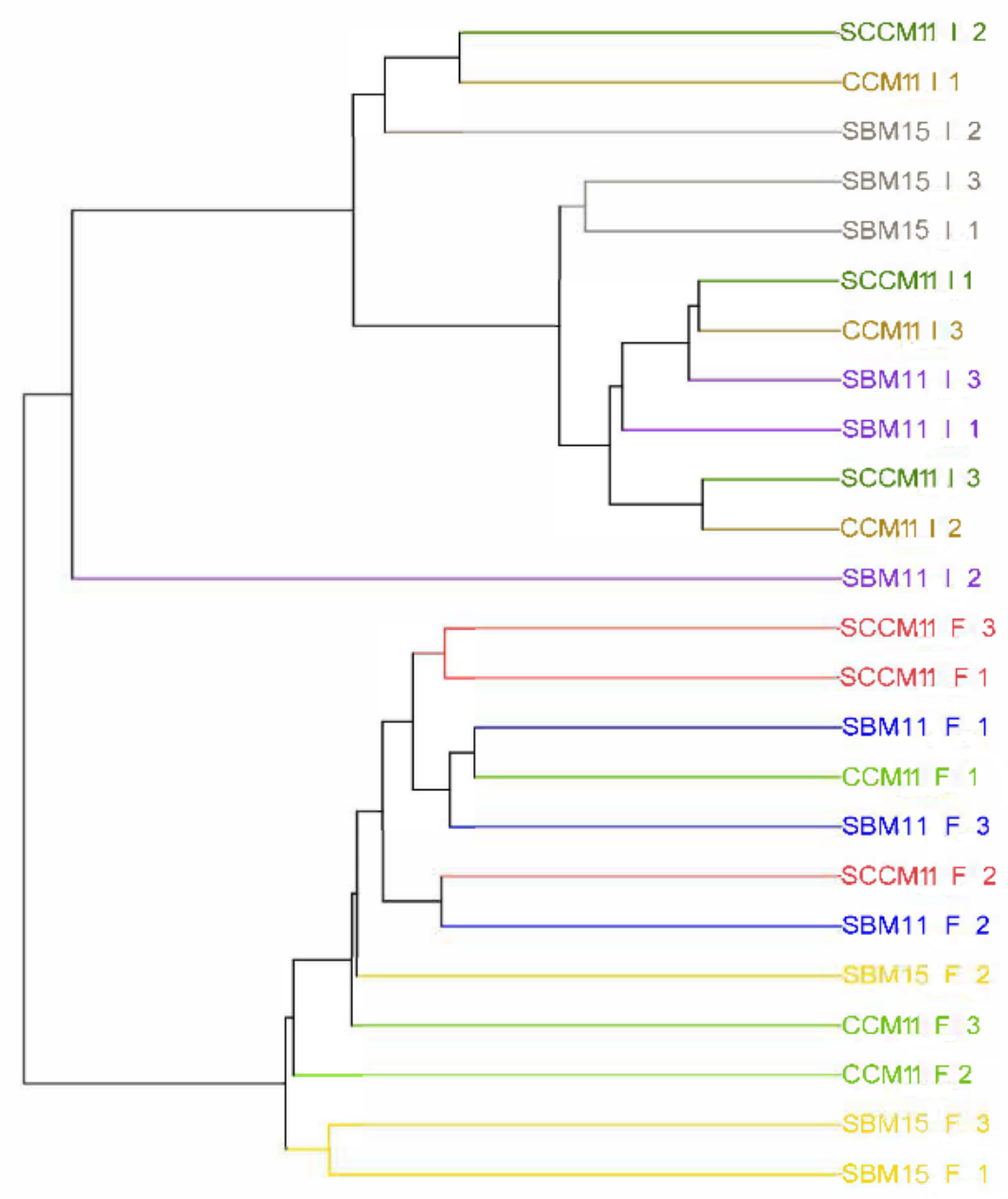

$$
\stackrel{\bullet}{0.01}
$$

Figure 2. Cluster analysis by the weighted unweighted pair group method with arithmetic means (UPGMA) for bacterial communities from different diets samples. SBM15 represents soybean meal (SBM) and the crude protein $(C P)$ level is 15\%. SBM11 represents SBM and the $C P$ level is $11 \%$. SCCM11 represents soybean-cottonseed-corn germ meal (SCCM) and the CP level is $11 \%$. CCM11 represents cottonseed-corn germ meal (CCM) and CP level is $11 \%$. The "I" represent ileum; " $F$ " represents feces. The number, in the end, is pig number (one to three pigs) and the same color means the same group. To make the figure clear, I did not put all pig number (one to six pigs) 


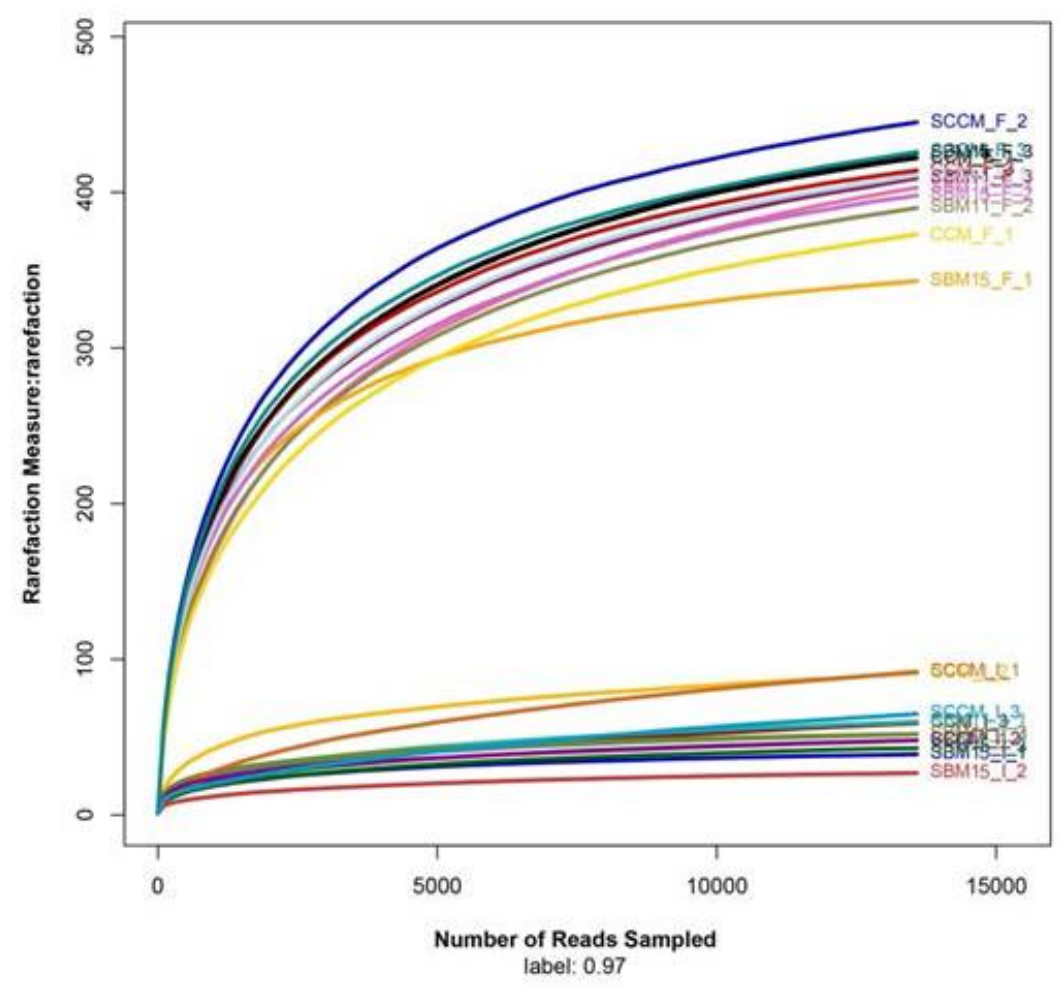

Figure 3. Rarefaction curve of bacterial $16 S$ rRNA sequences for different diets samples. OTUs are identified using $97 \%$ cutoffs. SBM15 represents soybean meal (SBM) and the crude protein (CP) level is 15\%. SBM11 represents SBM and the CP level is $11 \%$. SCCM11 represents soybean-cottonseed-corn germ meal (SCCM) and the CP level is 11\%. CCM11 represents cottonseed-corn germ meal (CCM) and CP level is 11\%. The "I" represent ileum; " $F$ " represents feces

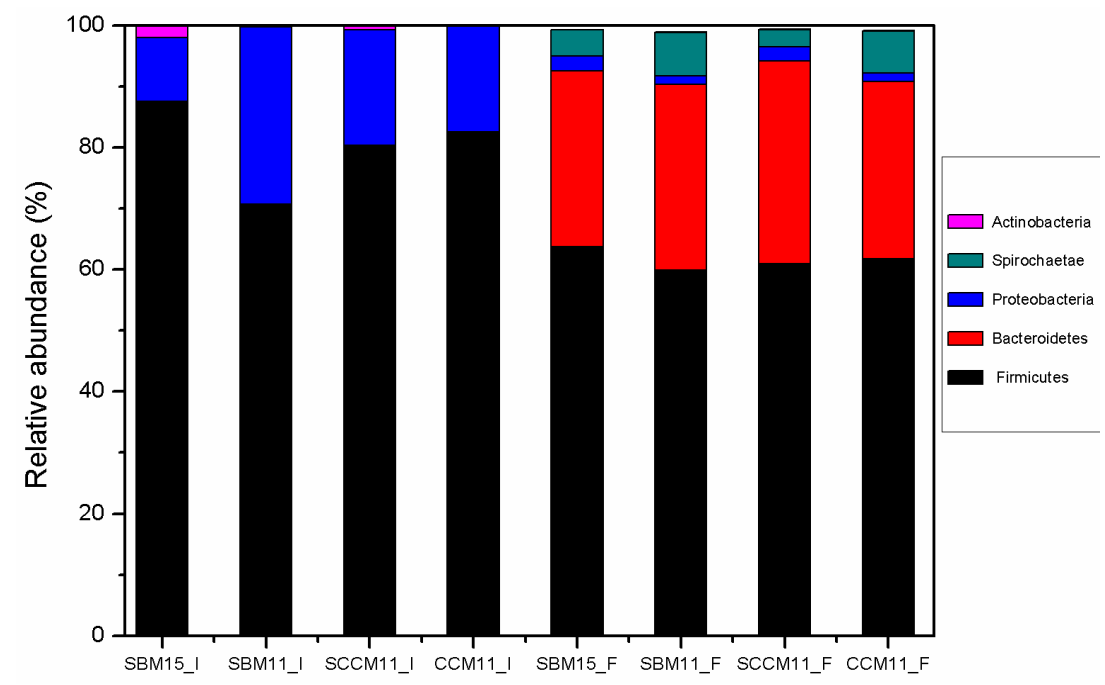

Figure 4. The relative abundance of ileum and feces microbiota general (percentages) at the phylum level in the finishing pigs fed different diets. SBM15 represents soybean meal (SBM) and the crude protein $(C P)$ level is 15\%. SBM11 represents SBM and the CP level is $11 \%$. SCCM11 represents soybean-cottonseed-corn germ meal (SCCM) and the CP level is $11 \%$. CCM11 represents cottonseed-corn germ meal (CCM) and CP level is 11\%. The "I" represent ileum; " $F$ " represents feces 


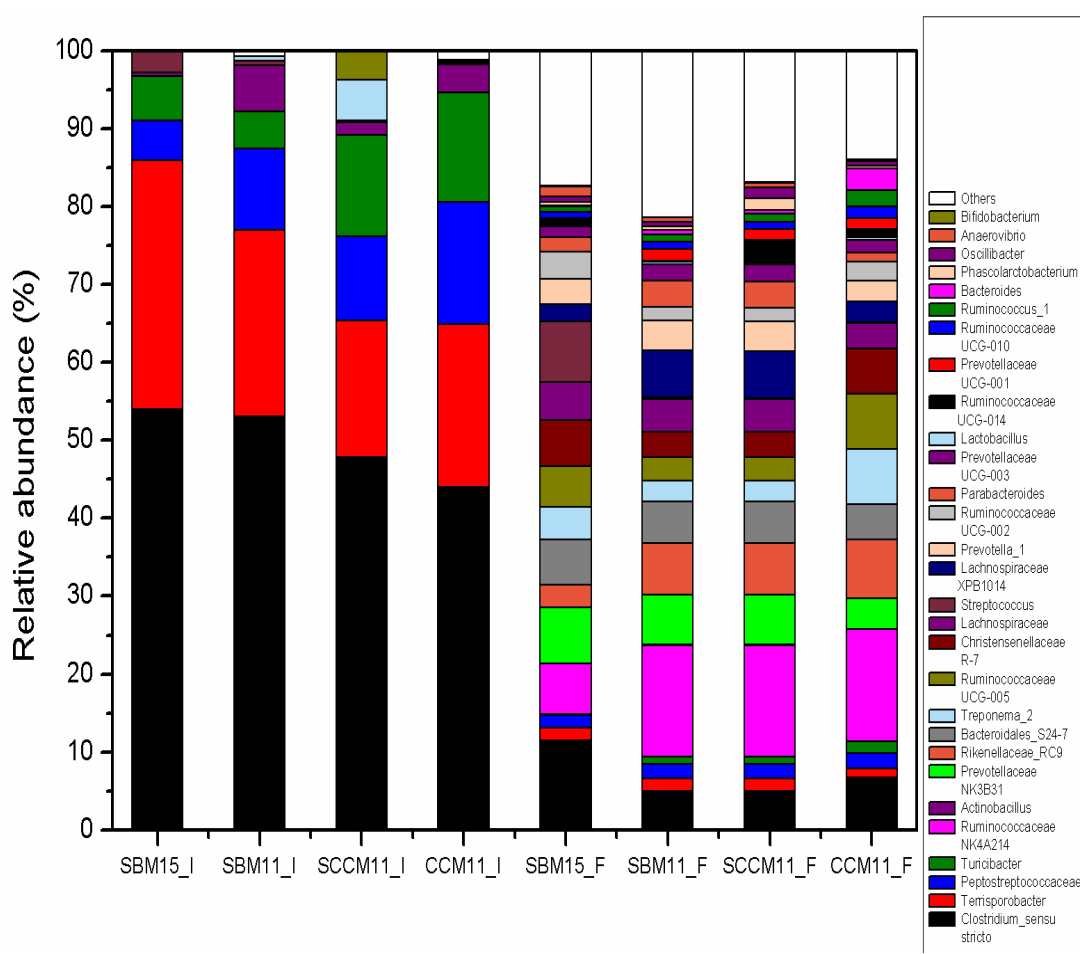

Figure 5. The relative abundance of ileum and feces microbiota general (percentages) at the genus level in the finishing pigs fed different diets. SBM15 represents soybean meal (SBM) and the crude protein (CP) level is 15\%. SBM11 represents SBM and the CP level is $11 \%$. SCCM11 represents soybean-cottonseed-corn germ meal (SCCM) and the CP level is $11 \%$. CCM11 represents cottonseed-corn germ meal (CCM) and CP level is 11\%. The "I" represent ileum; " $F$ " represents feces

Table 3. The relative abundance of microbiota genera (\%) that were significantly affected by the dietary treatment in the ileum and feces of finishing pigs $(n=6)$

\begin{tabular}{c|c|c|c|c|c|c}
\hline Items & Genus & SBM15 & SBM11 & SCCM11 & CCM11 $^{\mathrm{P}}$ & $\boldsymbol{P}$ value \\
\hline \multirow{5}{*}{ Ileum } & Actinobacillus & $0.501 \pm 0.051^{\mathrm{d}}$ & $5.930 \pm 0.671^{\mathrm{a}}$ & $1.596 \pm 0.212^{\mathrm{c}}$ & $3.562 \pm 0.789^{\mathrm{b}}$ & 0.001 \\
& Streptococcus & $2.895 \pm 0.728^{\mathrm{a}}$ & $0.567 \pm 0.367^{\mathrm{b}}$ & $0.237 \pm 0.230^{\mathrm{b}}$ & $0.195 \pm 0.257^{\mathrm{b}}$ & 0.003 \\
& Lactobacillus & $0.017 \pm 0.017^{\mathrm{c}}$ & $0.589 \pm 0.580^{\mathrm{b}}$ & $5.214 \pm 2.768^{\mathrm{a}}$ & $0.194 \pm 0.082^{\mathrm{b}}$ & 0.006 \\
& Bifidobacterium & $0.000^{\mathrm{c}}$ & $0.026 \pm 0.023^{\mathrm{b}}$ & $3.923 \pm 4.739^{\mathrm{a}}$ & $0.241 \pm 0.196^{\mathrm{b}}$ & 0.029 \\
\hline \multirow{5}{*}{ Feces } & Streptococcus & $7.785 \pm 5.620^{\mathrm{a}}$ & $0.172 \pm 0.139^{\mathrm{b}}$ & $0.077 \pm 0.065^{\mathrm{b}}$ & $0.057 \pm 0.055^{\mathrm{b}}$ & 0.023 \\
& Ruminococcaceae UCG-014 & $0.498 \pm 0.432^{\mathrm{b}}$ & $0.183 \pm 0.034^{\mathrm{b}}$ & $2.882 \pm 0.890^{\mathrm{a}}$ & $1.110 \pm 0.942^{\mathrm{b}}$ & 0.009 \\
& Prevotellaceae UCG-001 & $0.243 \pm 0.109^{\mathrm{b}}$ & $1.857 \pm 0.904^{\mathrm{a}}$ & $1.739 \pm 0.923^{\mathrm{a}}$ & $1.695 \pm 0.993^{\mathrm{a}}$ & 0.022 \\
& Ruminococcaceae UCG-010 & $0.862 \pm 0.478^{\mathrm{a}}$ & $0.691 \pm 0.133^{\mathrm{b}}$ & $0.941 \pm 0.144^{\mathrm{b}}$ & $1.502 \pm 0.245^{\mathrm{a}}$ & 0.039 \\
& Ruminococcus 1 & $0.414 \pm 0.013^{\mathrm{b}}$ & $0.555 \pm 0.344^{\mathrm{b}}$ & $0.987 \pm 0.585^{\mathrm{b}}$ & $2.125 \pm 0.262^{\mathrm{a}}$ & 0.002 \\
& Phascolarctobacterium & $0.508 \pm 0.177^{\mathrm{b}}$ & $0.545 \pm 0.455^{\mathrm{b}}$ & $1.496 \pm 0.158^{\mathrm{a}}$ & $0.360 \pm 0.231^{\mathrm{b}}$ & 0.004 \\
& Oscillibacter & $0.676 \pm 0.196^{\mathrm{b}}$ & $0.504 \pm 0.237^{\mathrm{b}}$ & $1.426 \pm 0.454^{\mathrm{a}}$ & $0.504 \pm 0.298^{\mathrm{b}}$ & 0.019 \\
& Anaerovibrio & $1.394 \pm 0.344^{\mathrm{a}}$ & $0.433 \pm 0.390^{\mathrm{b}}$ & $0.625 \pm 0.335^{\mathrm{b}}$ & $0.175 \pm 0.165^{\mathrm{c}}$ & 0.008 \\
\hline
\end{tabular}

Different letters in the same column identify significant differences at 0.05 level among parameters.

SBM15 represents soybean meal (SBM) and the crude protein (CP) level is 15\%. SBM11 represents SBM and the CP level is $11 \%$. SCCM11 represents soybean-cottonseed-corn germ meal (SCCM) and the CP level is $11 \%$. CCM11 represents cottonseed-corn germ meal (CCM) and CP level is $11 \%$ 


\section{Discussion}

With the development of next-generation sequencing techniques, we know the density of bacteria in the pig intestine represents as much as $10^{11}-10^{12}$ cells for every gram of gut contents and belongs to thousands of bacterial taxa (Rinninella, 2019). This is necessary to determine intestine microbiota diversity in pigs.

In this study, the LP diet, in which the protein level is $11 \%$, can affect the diversity of ileum and feces bacterial. This consists of previous reports (Rist et al., 2014). For ileum, the SCCM11 and CCM11 groups significantly increased the diversity of bacterial compared with the groups of SBM15 and SBM11. The possible reason is that the SCCM11 group is combined with SBM, CSM, CGM as the protein source, and the CCM11 group is combined with CSM, CGM. Different protein sources and combinations, due to their different protein structures, the amino acids released by digestion have a certain effect on microbiota diversity. It is beneficial for the small intestine microbe to utilize amino acids for metabolism activities. However, the bacterial diversity of the CCM11 group was less than the SCCM11 group. Gidlund et al. (2015) indicated that SBM has higher protein digestion than CSM. The reason may be due to lack of SBM, which is one of the protein sources, compared with SCCM11 group, the protein cannot be degraded well in the small intestine for CCM11 diet and intestine microbiota also cannot better-used amino acid for metabolism activities (Fan et al., 2015). For feces, the bacterial diversity of the SCCM11 group was significantly increased compared with the SBM15 group. The possible reason is that the SCCM11 group consisted of different sources not only enrich amino acid composition but also other abundant nutrition in the diet. The diversity of bacterial increased to adapt to the competition of bacterial for nutrition.

For bacterial structure, the present study showed that bacterial community structure is similar in the same intestine among the four groups. Zhao et al. (2010) indicated that intestinal microbiota structure is the result of natural choice. The reason may be that, during the long-term treatment, intestinal structure adapts to the competition relation of microbiota and the change of nutrition (Wu et al., 2011). However, contrary to the stable fecal microbiota, ileum microbiota displays pronounced compositional fluctuations. This is in agreement with the opinion of Jiang et al. (2013). The reason may be due to the different functions of the small intestine and large intestine. As we have known, the small intestine is the main place of nutrition digestion and absorption. It may enrich the activities of microbiota to used nutrition.

Recently, because of the potential impacts of host health, the effect of dietary protein on the intestinal microbiome in pigs is necessary to be attentive. This study focused on potential pathogenic and beneficial microorganisms. Also, the dietary treatment in the condition of this study modulated several abundances of gut microbiota in the phyla and genus levels.

At the phylum level, the present study showed that Firmicutes is the predominant bacterial in ileum among the four groups. This is in agreement with the opinion of Yang et al. (2018). Moreover, the relative abundance of Proteobacteria phyla in the ileum of the three LP groups was significantly increased compared with the SBM15 group, as previously shown in the microbiota study of pigs (Huang et al., 2020). The possible reason is that three LP diets adding more crystalline amino acids which are more easily to be absorbed by small intestinal compared with the normal protein diet. Meanwhile, it also increased the interest of Proteobacteria to utilize amino acid as a fermented protein. But the three LP groups had no effect on bacterial composition in feces 
compared with the SBM15 group. More studies demonstrate that a reduction in dietary protein content may result in a lower intestinal ammonia concentration, but not necessarily changes in the intestinal bacterial community of pigs (Heo et al., 2013; Rutherfurd et al., 2014). Our results may be insisted on the opinion. These results indicated that LP diets supplement crystalline amino acid has the potential to be available for large intestinal microbiota.

At the genus level, the abundance of Lactobacillus and Bifidobacterium of the SCCM11 group was increased in ileum compared to the SBM15 group. It is generally accepted that Lactobacillus is important to maintain intestinal health and can inhibit the growth of potential pathogenic groups (Zhang et al., 2018). Similar to Lactobacillus, Bifidobacterium was also shown to beneficial affect intestinal health (Zhang et al., 2020). This is in agreement with previous studies (Bindelle et al., 2010; Jiang et al., 2015). The reason may be that the SCCM11 group combined with different protein sources, which have a high-quality source can enrich amino acid composition and contribute to the development of Lactobacillus and Bifidobacterium.

In the feces, the relative abundance of Streptococcus and Anaerovibrio genus was higher and the abundance of Prevotellaceae was lower in the SBM15 group compared with three LP groups. Streptococcus genus also belongs to the lactic acid bacteria and some species have similar probiotic characteristics to Streptococcus. Also, some species are potential pathogens (Gómez-Gascón et al., 2016). The previous study reported that a reduction of dietary $\mathrm{CP}$ content diet from 230 to $130 \mathrm{~g} / \mathrm{kg}$ was associated with lower counts of pathogenic bacteria, such as Coliforms (Ye et al., 2011). In the present study, the abundance of Ruminococcus and Prevotellaceae of the SCCM11 and CCM11 group were increased. This is in general agreement with Zhou et al. (2015), where feeding an LP diet to pigs increased Prevotellaceae. Moreover, it was previously reported that Ruminococcus and Prevotellaceae were two of the predominant fiber-degrading bacterial species in the intestinal tracts of pigs (Zhao et al., 2017). The abundance of Bacteroides was also increased in the SCCM11 and CCM11 groups. The reason may be that Bacteroides has a better ability to decompose and use substrate. It was revealed that adding CSM and CGM increased the decomposition and utilization of fiber as a substrate in the large intestine for Bacteroides. In the SCCM11 group, the reads assigned to the genera Oscillibacter were present in slightly higher proportions than the other three groups. Oscillibacter has been identified as a valerate-producing anaerobe (Le Roy et al., 2020). Valerate as organic acids can reduce pathogenic bacteria of the intestine and endogenous losses (Park et al., 2014; Rodrigues et al., 2020).

\section{Conclusion}

The present study indicated that support crystalline amino acid to LP diet, in which the protein level is $11 \%$, may modulate the intestinal microbiota. Maybe due to the preferred location of some bacteria groups in the intestine, the effect on intestinal microbiota diversity, abundance, and composition are not consistent throughout the sampling sites in the current study. The present results showed that the SCCM11 group increased the bacterial diversity in ileum and feces and also increased the abundance of Lactobacillus which is important to maintain intestinal health and can inhibit the growth of potential pathogenic groups. However, the potential regulatory mechanism of the microbiota on the finishing pig health is still unclear, and further research is needed. 
Further studies are warranted to clarify the potential roles of this microbiota modulate to the health of finishing pigs according to DGGE technology.

Acknowledgments. This research has received funding from the National Basic Research Program of China [2013CB127306, 2017YFD0500506] and the College of Animal Science and Technology, Jilin Agricultural University.

\section{REFERENCES}

[1] Agyekum, A. K., Regassa, A., Kiarie, E., Kiarie, E., Nyachoti, C. M. (2016): Nutrient digestibility, digesta volatile fatty acids, and intestinal bacterial profile in growing pigs fed a distillers dried grains with solubles containing diet supplemented with a multienzyme cocktail. - Animal Feed Science and Technology 212: 70-80.

[2] Bindelle, J., Pieper, R., Leterme, P., Rossnagel, B., Van Kessel, A. G. (2010): Changes in intestinal microbial ecophysiology as related to the carbohydrate composition of barleys and oats cultivars in an in vitro model of the pig gastrointestinal tract. - Livestock Science 133: 151-153.

[3] Brestoff, J. R., Artis, D. (2013): Commensal bacteria at the interface of host metabolism and the immune system. - Nature Immunology 14: 676-684.

[4] Castillo, M., Martín-Orúe, S., Manzanilla, E., Badiola, I., Martin, M., Gasa, J. (2006): Quantification of total bacteria, enterobacteria and lactobacilli populations in pig digesta by real-time PCR. - Veterinary Microbiology 114: 165-170.

[5] Dersjant-Li, Y., Dusel, G. (2019): Increasing the dosing of a Buttiauxella phytase improves phytate degradation, mineral, energy, and amino acid digestibility in weaned pigs fed a complex diet based on wheat, corn, soybean meal, barley, and rapeseed meal. Journal of Animal Science 97(6): 2524-2533.

[6] Fan, P., Li, L., Rezaei, A., Eslamfam, S., Che, D., Ma, X. (2015): Metabolites of dietary protein and peptides by intestinal microbes and their impacts on gut. - Current Protein \& Peptide Science 16: 646-654.

[7] Gidlund, H., Hetta, M., Krizsan, S. J. (2015): Effects of soybean meal or canola meal on milk production and methane emissions in lactating dairy cows fed grass silage-based diets. - Journal of Dairy Science 98: 8093-8106.

[8] Gómez-Gascón, L., Cardoso-Toset, F., Tarradas, C., Gómez-Laguna, J., Maldonado, A., Nielsen, J., Olaya-Abril, A., Rodríguez-Ortega, M. J., Luque, I. (2016): Characterization of the immune response and evaluation of the protective capacity of $\mathrm{rSsnA}$ against Streptococcus suis infection in pigs. - Comparative Immunology, Microbiology \& Infectious Diseases 47: 52-59.

[9] González-Vega, J., Stein, H. H. (2012): Amino acid digestibility in canola-cottonsee sunflower-products fed to finishing pigs. - Journal of Animal Science 90: 4391-4400.

[10] Heo, J. M., Opapeju, F. O., Pluske, J. R., Kim, J. C., Hampson, D. J., Nyachoti, C. M. (2013): Gastrointestinal health and function in weaned pigs: a review of feeding strategies to control post-weaning diarrhoea without using in-feed antimicrobial compounds. Journal of Animal Physiology and Animal Nutrition 97: 207-37.

[11] Huang, J., Zhang, W., Fan, R., Liu, Z., Huang, T., Li, J., Du, T., Xiong, T. (2020): Composition and functional diversity of fecal bacterial community of wild boar, commercial pig and domestic native pig as revealed by $16 \mathrm{~S}$ rRNA gene sequencing. Archives of Microbiology 202(4): 843-857.

[12] Jiang, X. T., Peng, X., Deng, G. H., Sheng, H. F., Wang, Y., Zhou, H. W. (2013): Illumina sequencing of $16 \mathrm{~s}$ rRNA tag revealed spatial variations of bacterial communities in a mangrove wetland. - Microbial Ecology 66: 96-104. 
[13] Jiang, X. R., Agazzi, A., Awati, A., Vitari, F., Bento, H., Ferrari, A., Alborali, G. L., Crestani, M., Domeneghini, C., Bontempo, V. (2015): Influence of a blend of essential oils and an enzyme combination on growth performance, microbial counts, ileum microscopic anatomy and the expression of inflammatory mediators in weaned piglets following an Escherichia coli infection. - Animal Feed Science and Technology 209: 219-229.

[14] Le Roy, T., Van der Smissen, P., Paquot, A., Delzenne, N., Muccioli, G. G., Collet, J. F., Cani, P. D. (2020): Dysosmobacter welbionisgen. nov., sp. nov., isolated from human faeces and emended description of the genus Oscillibacter. - International Journal of Systematic and Evolutionary Microbiology 70(9): 4851-4858.

[15] Liao, S. F., Nyachoti, M. (2017): Using probiotics to improve swine gut health and nutrient utilization. - Animal Nutrition 3(4): 331-343.

[16] Lozupone, C., Lladser, M. E., Knights, D., Stombaugh, J., Knight, R. (2011): UniFrac: an effective distance metric for microbial community comparison. - ISME Journal 5: 169172.

[17] McDonald, J., Mullish, B. H., Pechlivanis, A., Liu, Z., Brignardello, J., Kao, D., Holmes, E., Li, J. V., Clarke, T. B., Thursz, M. R., Marchesi, J. R. (2018): Inhibiting Growth of Clostridioides difficile by Restoring Valerate, Produced by the Intestinal Microbiota. Gastroenterology 155(5): 1495-1507.

[18] Metzler-Zebeli, B. U., Ratriyanto, A., Jezierny, D., Sauer, N., Eklund, M., Mosenthin, R. (2009): Effects of betaine organic acids and inulin as single feed additives or in combination on bacteria populations in the gastrointestinal tract of weaned pigs. Archives of Animal Nutrition 63: 427-435.

[19] Morales, A., García, H., Sánchez, J. E. (2012): Apparent ileal amino acid digestibility and activities of trypsin and chymotrypsin in pigs fed sorghum-soybean meal diets supplemented with a microbial phytase. - Animal Feed Science and Technology 172: 247-251.

[20] National Research Council (NRC). (2012): Nutrient Requirements of Swine: Eleventh Revised Edition. - The National Academies Press, Washington DC.

[21] Park, S. J., Kim, J., Lee, J. S., Rhee, S. K., Kim, H. (2014): Characterization of the fecal microbiome in different swine groups by high-throughput sequencing. - Anaerobe 28: 157-162.

[22] Qiong, W, Garrity, G. M., Tiedje, J. M., Cole, J. R. (2007): Naïve Bayesian classifier for rapid assignment of rRNA sequences into the new bacterial taxonomy. - Applied and Environmental Microbiology 73: 5261-5267.

[23] Quast, C., Pruesse, E., Yilmaz, P., Gerken, J., Schweer, T., Yarza, P., Peplies, J., Glöckner, F. O. (2013): The silva ribosomal RNA gene database project: improved data processing and web-based tools. - Nucleic Acids Research 41: 590-596.

[24] Ren, W., Yu, R., Liu, G., Li, N., Peng, Y., Wu, M., Yin, Y., Li, Y., Fatufe, A. A., Li, T. (2013): DNA vaccine encoding the major virulence factors of Shiga toxin type 2e (Stx2e)-expressing Escherichia coli induces protection in mice. - Vaccine 31: 367-372.

[25] Rinninella, E., Cintoni, M., Raoul, P., Lopetuso, L. R., Scaldaferri, F., Pulcini, G., Miggiano, G., Gasbarrini, A., Mele, M. C. (2019): Food Components and Dietary Habits: Keys for a Healthy Gut Microbiota Composition. - Nutrients 11(10): 2393.

[26] Rist, V. T. S., Weiss, E., Sauer, N., Mosenthin, R., Eklund, M. (2014): Effect of dietary protein supply originating from soybean meal or casein on the intestinal microbiota of piglets. - Anaerobe 25: 72-79.

[27] Rodrigues, L. M., Neto, T., Garbossa, C., Martins, C., Garcez, D., Alves, L., de Abreu, M., Ferreira, R. A., Cantarelli, V. S. (2020): Benzoic Acid Combined with Essential Oils Can $\mathrm{Be}$ an Alternative to the Use of Antibiotic Growth Promoters for Piglets Challenged with E. coli F4. - Animals 10(11): 1978.

[28] Rutherfurd, S. M., Chung, T. K., Moughan, P. J. (2014): The effect of dietary microbial phytase on mineral digestibility determined throughout the gastrointestinal tract of the 
growing pig fed a Low-P, Low-Ca corn-soybean meal diet. - Animal Feed Science and Technology 189: 130-133.

[29] Sbardella, M., Perina, D. P., Andrade, C., Santos, C. B., Cairo, P. L. G., Marques, E. L. S., Rezende, R. P., Costa, L. B., Miyada, V. S. (2016): Effects of dietary hop $\beta$-acids or colistin on the performance, nutrient digestibility, and intestinal health of weanling pigs. - Animal Feed Science and Technology 217: 67-75.

[30] Schloss, P. D., Dirk, G., Westcott, S. L. (2011): Reducing the effects of PCR amplification and sequencing artifacts on 16s rRNA-based studies. - PLoS One 6: 273275.

[31] Wellock, I. J., Fortomaris, P. D., Houdijk, J. G. M., Kyriazakis, I. (2006): The effect of dietary protein supply on the performance and risk of post-weaning enteric disorders in newly weaned pigs. - Animal Science 82: 327-335.

[32] Wu, G. D., Chen, J., Hoffmann, C., Bittinger, K., Chen, Y.-Y., Keilbaugh, S. A., Bewtra, M., Knights, D., Walters, W. A., Knight, R., Sinha, R., Gilroy, E., Gupta, K., Baldassano, R., Nessel, L., Li, H., Bushman, F. D., Lewis, J. D. (2011): Linking long-term dietary patterns with gut microbial enterotypes. - Science 334(6052): 105-108.

[33] Yang, H., Xiao, Y., Wang, J., Xiang, Y., Gong, Y., Wen, X., Li, D. (2018): Core gut microbiota in Jinhua pigs and its correlation with strain, farm and weaning age. - Journal of Microbiology (Seoul, Korea) 56(5): 346-355.

[34] Ye, X., Li, J., Lu, M., Deng, G., Jiang, X., Tian, Y., Quan, Y. C. Jian, Q. (2011): Identification and molecular typing of streptococcus agalactiae isolated from pondcultured tilapia in China. - Fisheries Science 77: 623-632.

[35] Zhang, W., Ji, H., Zhang, D., Liu, H., Wang, S., Wang, J., Wang, Y. (2018): Complete Genome Sequencing of Lactobacillus plantarum ZLP001, a Potential Probiotic That Enhances Intestinal Epithelial Barrier Function and Defense Against Pathogens in Pigs. Frontiers in Physiology 9: 1689.

[36] Zhang, H., Wielen, N. V., Hee, B. V., Wang, J., Hendriks, W., Gilbert, M. (2020): Impact of Fermentable Protein, by Feeding High Protein Diets, on Microbial Composition, Microbial Catabolic Activity, Gut Health and beyond in Pigs. - Microorganisms 8(11): 1735 .

[37] Zhao, L. D. (2010): Ecological analysis of the amino acid metabolism in pig small intestinal bacteria. - Chin J Anim Sci 43: 83-85.

[38] Zhao, G., Zhou, L., Dong, Y., Cheng, Y., Song, Y. (2017): The gut microbiome of hooded cranes (Grus monacha) wintering at Shengjin Lake, China. - MicrobiologyOpen 6(3): e00447.

[39] Zhou, L. P., Fang, L. D., Sun, Y., Su, Y., Zhu, Y. W. (2015): Effects of the dietary protein level on the microbial composition and metabolomic profile in the hindgut of the pig. - Anaerobe 38: 61-69. 